\title{
Precipitation of Heavy Organics (Asphaltenes) from Crude Oil Residue Using Binary Mixtures of n-Alkanes
}

\author{
O. Achugasim*, I. E. Ekpo \\ Department of Pure and Industrial Chemistry, University of Port Harcourt, Port Harcourt, Nigeria \\ Email: ${ }^{*}$ Ozioma.achugasim@uniport.edu.ng
}

Received 25 December 2014; accepted 16 January 2015; published 20 January 2015

Copyright (C) 2015 by authors and Scientific Research Publishing Inc.

This work is licensed under the Creative Commons Attribution International License (CC BY).

http://creativecommons.org/licenses/by/4.0/

(c) () Dpen Access

\section{Abstract}

Two solvent mixtures: n-pentane/n-hexane and $n$-heptane/n-octane at ten different percentage ratios were used to dissolve $2.5 \mathrm{~g}$ of vacuum distilled Anthan crude oil residue $\left(500^{\circ} \mathrm{C}\right)$. The crude oil/n-alkane mixture in different conical flasks was stoppered, shaked mechanically and allowed to stand overnight. The resultant solution was subsequently filtered using a vacuum pump to afford the different weights of the residue (asphaltenes). The result of the weights of asphaltenes obtained at the different ratios of solvent mixtures showed that the highest amount of precipitate was obtained at $100 \%$ n-pentane solvent. Also there was a sharp increase in the amount of asphaltenes precipitated when the percentage ratio of n-pentane to $n$-hexane precipitant was 40:60 and when the ratio of $n$-heptane to n-octane precipitant was 30:70. A good understanding of the contribution of the different $n$-alkane solvents in the precipitation of asphaltenes is very necessary to flow assurance of crude oils in terms of solid precipitation.

\section{Keywords}

Asphaltenes, Precipitants, n-Heptane, n-Octane, Crude Oil, Binary Mixtures

\section{Introduction}

The most important economic liquid, perhaps the least understood, is crude oil. It is a mixture of many compounds prominent among which are the hydrocarbons [1]. The non-hydrocarbon components are small and very important. Their presence or absence impacts so much on the economic value of crude oils.

The production, storage and eventual transportation of crude oils are fraught with many problems. These problems among others are spillage and solid precipitation. While spillage is most of the time man-made and

${ }^{*}$ Corresponding author.

How to cite this paper: Achugasim, O. and Ekpo, I.E. (2015) Precipitation of Heavy Organics (Asphaltenes) from Crude Oil Residue Using Binary Mixtures of n-Alkanes. Advances in Chemical Engineering and Science, 5, 96-101.

http://dx.doi.org/10.4236/aces.2015.51010 
controllable, solid precipitation is not. Solid precipitation could result from either the hydrocarbon or the nonhydrocarbon components of crude oil. At reservoir conditions, the light and heavy ends of crude oil are mutually soluble forming one phase. Variations in temperature, pressure and chemical compositions of crude oils may alter the mutual solubility of its components leading to the precipitation of the heavy ends out of the mixture [2]. Some of these solid precipitates are: ashphaltenes, waxes, resins, formation solids, diamondoids (adamantanesalkylated and non-alkylated), etc. All of these solid precipitates are organic compounds and are usually referred to as heavy organics (HO). These heavy organics could cause anything from mere suspension of solids in crude oil pipelines to complete blockage and clogging of flow lines. This has been known to cause serious damage to pipelines, storage vessels and processing equipment [3].

The increased demand in offshore crude oil production and enhanced oil recovery by miscible displacement, have added to the quest for further insight in the solubility dynamics of petroleum fluid components and the complex phase behavior of crude oils.

Among the heavy organics mentioned above, the asphaltenes seems to be the most complex in terms of chemical structure and behavior. It is the least understood and ironically the most studied of the heavy organics in crude oil. Based on experimental evidence/observation, asphaltenes have been described as the fraction of petroleum that is insoluble in an excess of low boiling liquid hydrocarbon but is soluble in aromatic solvents at ambient temperatures. It has also been defined as the percentage by weight of petroleum material that is insoluble in n-heptane but soluble in hot benzene [4] [5].

A good understanding of the process of precipitation of asphaltenes is highly necessary in the correct understanding of the complex phase behavior of crude oils which contain solid precipitates. Also, sound knowledge of the conditions that encourage or discourage precipitation of asphaltenes is a sine-quo non to achieving crude oil stability in pipelines and storage facilities. Asphaltenes are resistant to cracking leading to decreased yield of petroleum distillates. They are also very difficult to biodegrade making them undesirable from petroleum waste management point of view [6] [7]. The importance of researches in the process of asphaltene precipitation cannot be overemphasized. There are at least three conditions/factors that affect asphaltene precipitation. They are temperature, pressure and the chemical composition of the surrounding fluid [8]. Among these factors, the chemical composition of the surrounding fluid is the greatest factor affecting asphaltene precipitation [9].

Consequently, precipitation of asphaltenes by n-alkanes solvents deserves good attention. Several n-alkane solvents have been used by few researchers in the study of deposition of asphaltenes. These include n-pentane, n-hexane, n-heptane, n-octane, n-nonane, etc. [10] [11]. Okoye et al. (2011) have studied the precipitation using solvents of different polarities and carbon number [12].

The truth is that in reservoirs, pipelines and storage facilities, crude oil does not contain just one n-alkane precipitant of asphaltenes. Mixtures of alkanes in different ratios are the culprits. Studies into these mixtures of alkanes instead of just one alkane solvent will give a closer insight into what is responsible for the precipitation of asphaltenes and help in proffering solution to the different flow assurance problems encountered in the oil industry because of asphaltene precipitation.

In this study, the precipitation of asphaltenes from crude oil by binary mixtures of n-alkane solvents (heptane/octane) and (pentane/hexane) in different percentages has been investigated.

\section{Materials and Methods}

About $2.5 \mathrm{~g}$ of vacuum distilled Anthan crude oil residue $\left(500^{\circ} \mathrm{C}\right)$ was dissolved in different solvent mixtures at different percentage ratios in a conical flask at room temperature. The solvent mixtures were n-pentane/n-hexane and n-heptane/n-octane in the percentage ratios of 90:10, 80:20, 70:30, 60:40, 50;50, 40:60, 30:70, 20:80, 10:90 respectively. The crude oil/n-alkane mixtures in the flasks were stoppered and shaked in a mechanical shaker for one hour and allowed to stand overnight. The resultant solution was subsequently filtered and the weights of the solid residue (asphaltenes) were taken after drying.

\section{Results and Discussion}

The percentage weights of asphaltenes obtained from the various ratios of the solvent mixtures is presented in Tables 1-3. It is notable that for $C_{5}: C_{6}$ system at $100 \%$ n-pentane solvent, the highest amount of insoluble was precipitated. This is in line with previous researches on the amount of insoluble precipitated in relation to the number of carbon atoms in the precipitant (solvent) [6]. The result shows that the amount of precipitates ob- 
Table 1. Weights of asphaltene precipitates from the different ratios of n-alkane mixtures.

\begin{tabular}{cccc}
\hline Test & \% Ratio of Solvent Composition & Weight $(\mathrm{g})$ of Precipitates $\left(\mathrm{C}_{5}: \mathrm{C}_{6}\right)$ & Weight $(\mathrm{g})$ of Precipitates $\left(\mathrm{C}_{7}: \mathrm{C}_{8}\right)$ \\
\hline 1 & $100: 10$ & 2.18 & 3.92 \\
2 & $90: 10$ & 1.99 & 3.29 \\
3 & $80: 20$ & 1.90 & 3.05 \\
4 & $70: 30$ & 1.56 & 2.92 \\
5 & $60: 40$ & 1.47 & 2.83 \\
6 & $50: 50$ & 1.45 & 3.28 \\
7 & $40: 60$ & 1.63 & 3.44 \\
8 & $30: 70$ & 1.50 & 5.12 \\
9 & $20: 80$ & 1.62 & 4.32 \\
11 & $10: 90$ & 1.28 & 5.08 \\
\hline
\end{tabular}

Table 2. Weights of asphaltene precipitates from the different ratios of n-pentane/n-hexane mixture.

\begin{tabular}{ccc}
\hline Test & \% Ratio of Solvent Composition $\left(\mathrm{C}_{5}: \mathrm{C}_{6}\right)$ & \% Weight of Precipitates \\
\hline 1 & $100: 00$ & 2.18 \\
2 & $90: 10$ & 1.99 \\
3 & $80: 20$ & 1.90 \\
4 & $70: 30$ & 1.56 \\
5 & $60: 40$ & 1.47 \\
6 & $50: 50$ & 1.45 \\
7 & $40: 60$ & 1.63 \\
9 & $30: 70$ & 1.50 \\
10 & $20: 80$ & 1.62 \\
11 & $10: 90$ & 1.28 \\
\hline
\end{tabular}

Table 3. Weights of asphaltene precipitates from the different ratios of n-heptane/n-octane mixture.

\begin{tabular}{ccc}
\hline Test & \% Ratio of Solvent Composition $\left(\mathrm{C}_{7}: \mathrm{C}_{8}\right)$ & \% Weight of Precipitates $\left(\mathrm{C}_{7}: \mathrm{C}_{8}\right)$ \\
\hline 1 & $100: 00$ & 3.92 \\
2 & $90: 10$ & 3.29 \\
3 & $80: 20$ & 3.05 \\
4 & $70: 30$ & 2.92 \\
5 & $60: 40$ & 2.83 \\
6 & $50: 50$ & 3.28 \\
7 & $40: 60$ & 3.44 \\
9 & $30: 70$ & 5.12 \\
10 & $20: 80$ & 4.32 \\
11 & $10: 90$ & 5.08 \\
\hline
\end{tabular}


tained decreased from a maxima where the solvent of precipitation was $100 \%$ pentane to a minima where the solvent of precipitation was $100 \%$ hexane (Figures 1-3). The amount of asphaltenes precipitated between these two extremes at the different solvent ratios did not give any predictable gradation. The instability may be as a result of the different phase behavior of the precipitates. The solids dissolved and aggregated at different solvent ratios though not in a predictable manner.

The case is not different with the $\mathrm{C}_{7}: \mathrm{C}_{8}$ system. The amount of precipitate obtained at $100 \% \mathrm{n}$-heptane as the solvent is greater than that from $100 \%$ n-octane solvent.

It is interesting to note the sharp increase in the amount of asphaltenes obtained at $\mathrm{C}_{5}: \mathrm{C}_{6}(40: 60) \mathrm{cm}^{3}$ and $\mathrm{C}_{7}: \mathrm{C}_{8}(30: 70) \mathrm{cm}^{3}$. This may be an indication that optimum amount of precipitate is obtained at certain ratios of n-alkane solvent mixtures in crude oil, not necessarily at higher percentage of lower n-alkanes.

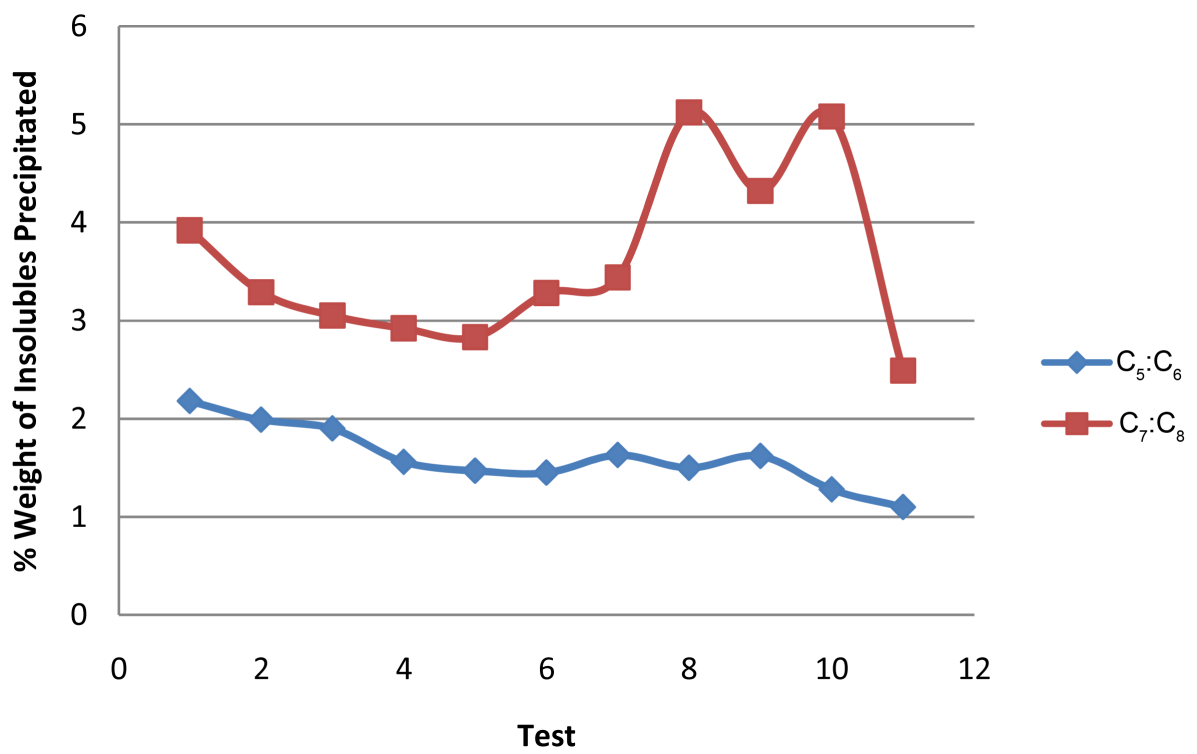

Figure 1. Plot of the weight of asphaltenes obtained from the different ratios of n-alkane mixtures (tests).

\section{$\mathrm{C}_{5}: \mathrm{C}_{6}$}

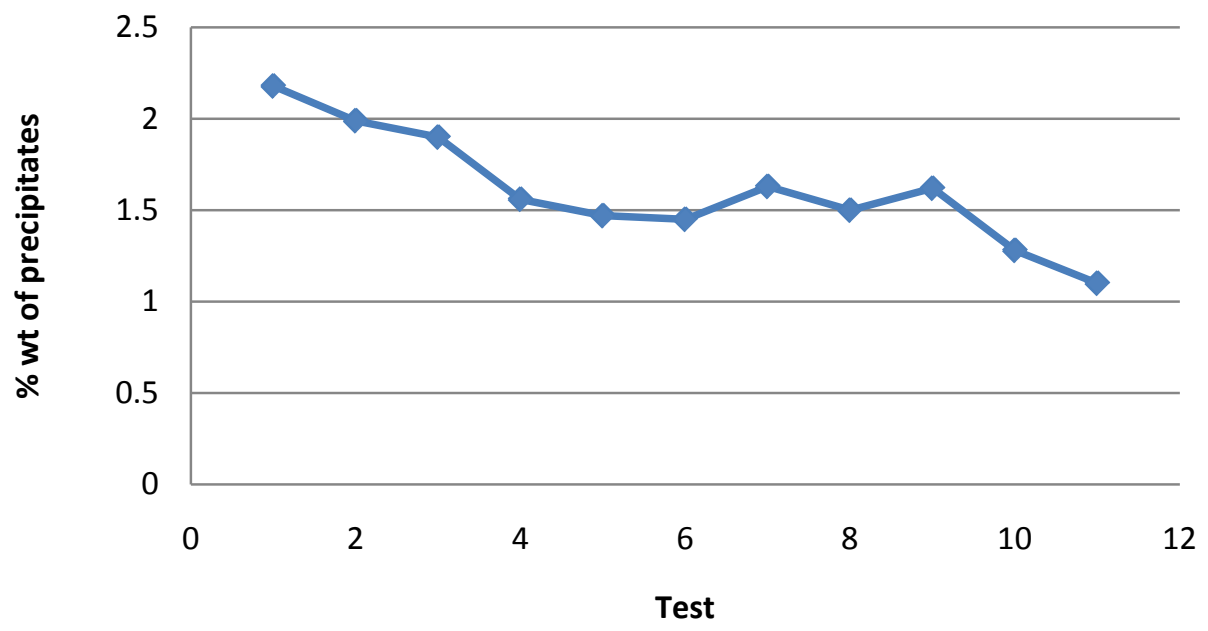

Figure 2. Plot of the weight of asphaltenes obtained from different ratios of n-pentane/n-hexane mixtures (tests). 


\section{$\mathrm{C}_{7}: \mathrm{C}_{8}$}

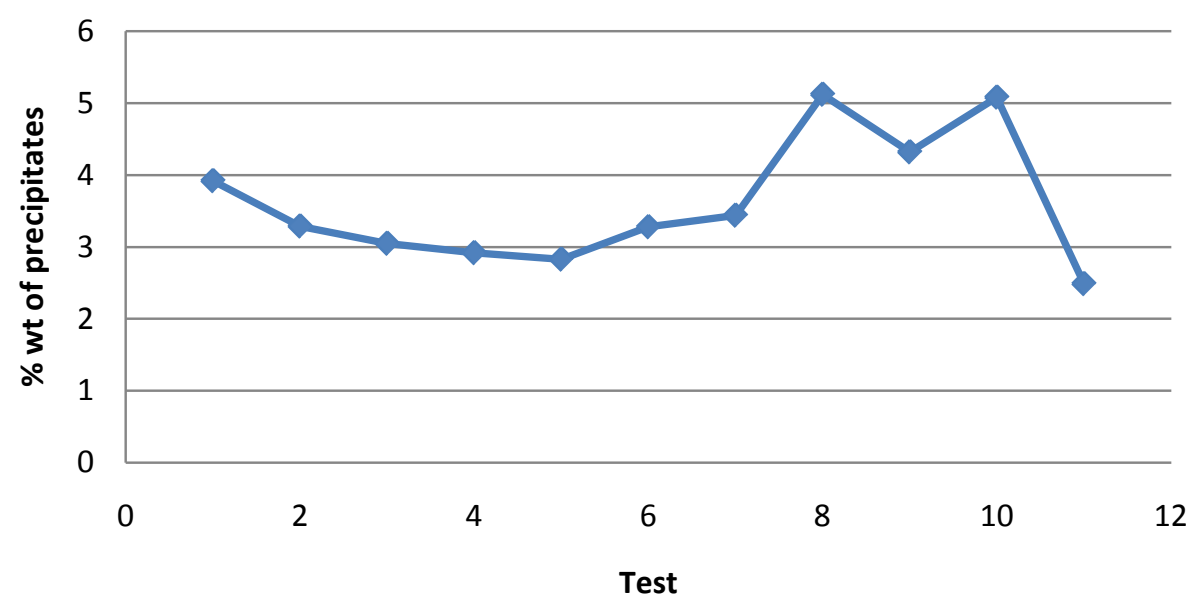

Figure 3. Plot of the weight of ashphaltenes obtained from different ratios of n-heptane/n-octane mixtures (tests).

\section{Conclusion}

The precipitation of asphaltenes from crude oil with single n-alkane solvent is not the same with its precipitation with mixtures of n-alkanes. The amount of asphaltenes precipitated in asphaltenes varies with the number carbon atoms in the solvent. Behavior of asphaltenes precipitated by binary solvent system of $\mathrm{C}_{5} / \mathrm{C}_{6}$ and $\mathrm{C}_{7} / \mathrm{C}_{8}$ may be an indication of what goes on during the actual precipitation of asphaltenes in crude oils in pipelines, storage facilities, etc.

\section{Acknowledgements}

The researchers are grateful to the Research and Development (R\&D) division of the Nigerian National Petroleum Cooperation (NNPC) for the provision of the vacuum distilled crude oil residue used in this study. They are also grateful to the expert advice and explanations given by Dr. S.E. Ofodile, Former Manager (R\&D) of the NNPC.

\section{References}

[1] Ojinnaka, C., Osuji, L. and Achugasim, O. (2012) Remediation of Hydrocarbons in Crude Oil Contaminated Soil Using Fenton's Reagent. Environmental Monitoring and Assessment, 184, 6527-6540. http://dx.doi.org/10.1007/s10661-011-2438-3

[2] Vazquez, D. and Mansoori, G.A. (2000) Analysis of Heavy Organic Deposits Based on Identification and Measurement of Petroleum Precipitates. Journal of Petroleum Science and Engineering, 26, 49-56. http://dx.doi.org/10.1016/S0920-4105(00)00020-6

[3] Hunt, J.M. (1996) Petroleum Geochemistry and Geology. Freedman, New York, 9.

[4] Hyne, N.J. (2001) Non-Technical Guide to Petroleum Geology, Exploration, Drilling and Production. Penwell, Taxes, 4.

[5] Kawanaka, S., Park, S.J. and Mansoori, G.A. (1991) Organic Deposition from Reservoir Fluids—A Thermodynamic Predictive Technique. S.P.E Reservoir Engineering Journal, 24, 283.

[6] Achugasim, O., Ojinnaka, C. and Osuji, L. (2013) Management of Petroporphyrins in a Crude Oil Polluted Environment. European Chemical Bulletin, 2, 794-796.

[7] Speight, J.G. (1999) The Chemistry and Technology of Petroleum. Marcel Decker, New York, 412-464. http://dx.doi.org/10.1201/9780824742119.ch10

[8] Leonartaritis, K.J. and Mansoori, G.A. (1988) Asphaltene Deposition. A Survey of Field Experiences and Research Approaches. Journal of Petroleum Science and Engineering, 1, 229. http://dx.doi.org/10.1016/0920-4105(88)90013-7 
[9] Kokal, S.C. and Sayeh, S.G. (1995) Asphaltenes: The Cholesterol of Petroleum. SPE 29787. SPE Middle East Oil Show, Bahrain, 11-14.

[10] Hirschberg, A., DeJong, L.N., Schipper, B.A. and Mayers, J.G. (1984) Influence of Temperature and Pressure on Asphaltene Flucculation. Society of Petroleum Engineering Journal, 24, 283. http://dx.doi.org/10.2118/11202-PA

[11] Kokal, S.C., Nayman, J., Sayeh, S.G. and George, A.E. (1992) Measurement and Correlation of Ashphaltene Precipitation from Heavy Oils by Gas Injection. Journal of Canadian Petroleum Technology, 31, 24. http://dx.doi.org/10.2118/92-04-01

[12] Okoye, I.P., Ofodile, S.E. and Chukwu, O.C. (2011) The Effect of Different Solvent Polarity on the Precipitation of Heavy Organics from a Crude Oil Deposit in the Niger Delta. Scienctia Africana, 10, 9-15. 
Scientific Research Publishing (SCIRP) is one of the largest Open Access journal publishers. It is currently publishing more than 200 open access, online, peer-reviewed journals covering a wide range of academic disciplines. SCIRP serves the worldwide academic communities and contributes to the progress and application of science with its publication.

Other selected journals from SCIRP are listed as below. Submit your manuscript to us via either submit@scirp.org or Online Submission Portal.
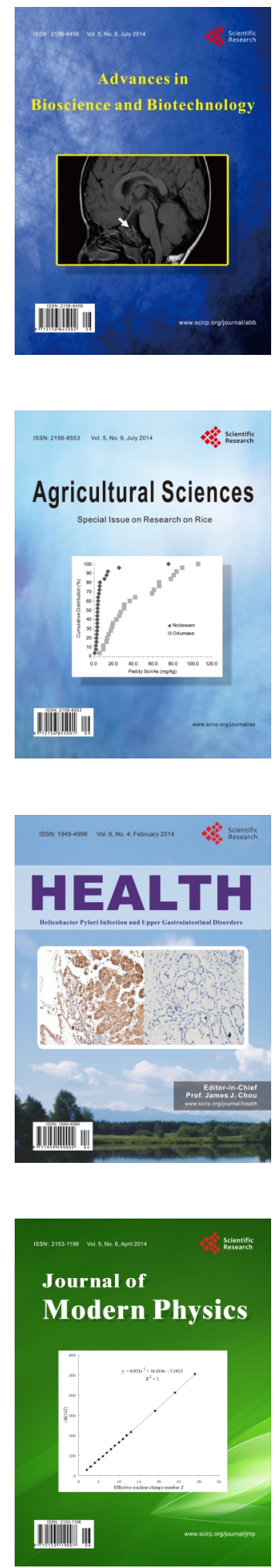
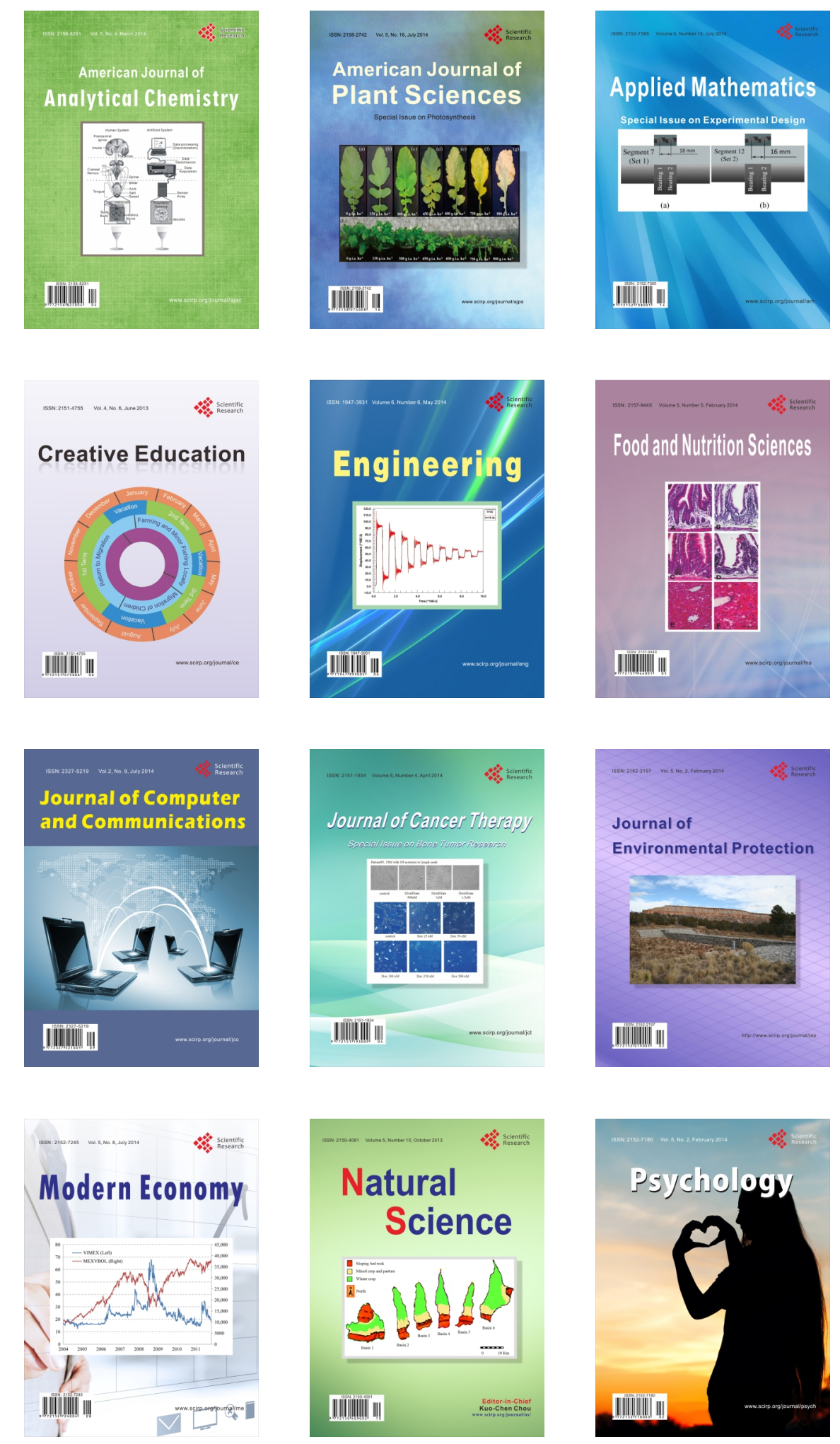